last. First from Bournemouth and Weymouth, where they were found not unfrequently dead on the shore. Again, one of the Leigh"shrimpers" took about a dozen specimens in his trawl net near Sheerness, at the mouth of the Thames. Another two specimens weie taken Iikewise in a shrimp trawl off Harwich. None of these survived, no doubt having been too long in the trawl net, which is frequently three or more hours in the water. Dead specimens of these were sent for my observation, by $\mathrm{Mr}$. Andrew, the aquarium fish collector of Southend-on-Sea. $\mathrm{He}$ says the Essex fishermen call them red dorees, but none remember having seen them on that coast before this year.

Royal Aquarium, Westminster, July 6 JOHN T. CARRINGTON

\section{Habits of Ants}

My attention was lately called by a friend to the operations of a party of ants. The theatre of their work was a cherry-tree partly decayed in the centre. From this portion of the tree the busy creatures were bringing forth small grains of sawdust-like débris. These particles were conveyed to the prominence left by an amputated branch, and thrown over to the ground, a distance of about five feet. The particles were passed on from one ant to another-as water-buckets were at old-tine fres. Nor was this all, for on the ground below, another party removed the accumulated material. In this connection the reader should consult a remarkable note on page 2 i of Kerner's "Flowers and their Unbidden Guests" to further illustrate the intelligence of ants and their recognition of the principle of division of Iabour. I am nnable to state the species of ant I observed, as I am not an entomologist. It was a rather large red ant.

W. WhITMAN BaILEY

Brown University, Providence, R.I. (U.S.), June I 7

\section{WILLIAM FOTHERGILI COOKE}

TIIERE has slipped away noiselessly and quietly one of England's scientific pioneers and one of the world's bencfactors. Sir William Fothergill Cooke was the father of electric telegraphy. Born in I806, educated in Durham, where his father was a professor, he joined the East India Company's military service in 1826, from which he retired in 1835 to study anatomy and physiology in Paris and Heidelberg. He was very clever at wax modelling. In 1836 a lecture on Schilling's telegraph directed his attention to the electric telegraph. His was the active sanguine mind that saw the great future of telegraphy before him, and that, in spite of supineness and unbelief, forced the new agent on an unwilling world. He was not an inventor nor a discoverer, but he was a farseeing, practical man, with a determined will, indomitable energy, and of great resources. Associated with Wheatstone, he established telegraphy as a commercial undertaking. The first experimental line in England was put up in 1837. The first Electric Telegraph Company was incorporated in 1844 . The first cable was laid in $185 \mathrm{I}$. Now the world is one network of wires, and while the pioneer of this great system is carried to his grave, representatives from every civilised nation of the earth meet in telegraphic parliament in London without heaving one sigh or casting one thought

"O'er the grave where our hero we buried."

\section{THE COMPARATIVE ANATOMY OF MAN'} II.

\section{The Andaman Islanders (continued)}

$\mathrm{H}$

THERTO the osteological characters of these people have only been known from one skeleton, briefly described by Prof. Owen, two crania by Mr. Busk, and two by Prof. Quatrefages. During the last half year, the College museum has received a valuable series of skeletons, collected, at the request of Sir Joseph Fayrer, by the late

r Abstract of Prof. Flower's Hunterian Lectures, delivered at the Royal College of Surgeons, commensing on Wednesday, March $\$$. Continued from p. 225 .
Dr. J. Dougall, senior medical officer at Port Blair; others have been lent for the purpose of illustrating this course by Professors Rolleston and Allen Thomson, amounting altogether to nineteen skeletons, and about thirty crania.

The common estimate among Europeans, which is fairly correct for averages, is that the length of the femur is to the height of the living person as 275 is to $I, \infty 00$. Only one of the above-mentioned Andamanese skeletons has been articulated, but this shows exactly the same proportion. Calculated on this basis, the average height of the skeletons of males would be 4 feet 9 inches, the tallest being 5 feet 3 inches, and the shortest 4 feet 6 inches. The average height of the ten skeletons of females would be 4 feet 6 inches, the tallest being 4 feet ro inches, the shortest 4 feet 3 inches.

Attention was first drawn to the fact that the proportions of the different segments of the limbs might differ in various races by the announcement in 1799 , by White, of Manchester, since amply confirmed, that the forearm of the Negro is proportionally longer than that of the European. Unfortunately, skeletons of most races are so rare in collections, that we have at present but few reliable data on this subject, and it is only when a sufficient number can be obtained, on which to found a fair average, that any satisfactory law can be established.

The first ratio, or index, is that obtained by the comparison of the entire upper and lower limbs with each other, the intermembral index, or the length of the humerus and radius added together, as compared with that of the femur and tibia, the latter being taken as Ioc. This ratio, in the nineteen Andaman skeletons, is 68.3 ; in fourteen Europeans, measured in the same manner, $69^{\circ}$, showing a slight diminution in the length of the arm of the former, as compared with the latter. This has been also found by Broca, to be the case with African Negroes. The femoro-humeral index is the ratio of the humerus to the femur, the latter being taken as roo. In Europeans, according to Prof. Flower's and Broca's measurements, this is 72 to 73 ; in Negroes, according to Broca, 68.9 ; in the Andamanese, 69.8 ; showing that in both the latter races the humerus is relatively shorter than the femur. The femoro-tibial index is the length of the tibia to the femur, the latter being roo. In Europeans, this is $82 ;$ in Negroes, according to Prof. Humphry, 847 ; in the Andamanese, almost exactly the same, $84^{\circ} 5$. The humero-radial index, or the length of the radius, compared to the humerus is, perhaps, the most important, as being subject to greater variations in different races. In nine Europeans measured by Broca, it is $73^{\circ} 9$; in fourteen Europeans in the College Museum, it is exactly the same; in fifteen Negroes measured by Broca, $79^{\prime} 4$; in the nineteen Andamanese, 8I. Thus the differential characters of the Andamanese, as compared with Europeans, in respect to the proportions of the limb-bones, lie mainly in the greater length of the distal segment of each limb as compared with the proximal segment, a peculiarity most especially manifested in the upper extremity.

In the Bulletin of the Paris Anthropological Society of last year, Broca called attention to the form of the scapula as a race-character, and showed that one of the principal modifications of the form of this bone could be expressed by an index formed of a ratio between the two chief diameters of the bone, i.e., the length from the posterior superior angle (C) to the inferior angle (D), and the breadth from the middle of the posterior margin of the glenoid cavity (A) to the point on the posterior or vertebral border from which the spine arises (B). The ratio of the length (CD) to the breadth (A B), the latter being 100 , is called the scapular index. In the anthro. poid apes the index varies between 70 and 100 , and in most of the lower forms of monkeys and other mammals, it is considerably higher. A high index is, therefore, a sign of inferiority. Broca found that the average in 
twenty-three Europeans was $65^{\circ} 91$, and in 200 scapulæ of Europeans, measured by Dr. Garson, the average index was $65^{\circ} 2$. The twenty-five Negro skeletons in the Paris Museum gave an average scapular index of 68.16 , and the six scapulæ of the three Negro skeletons in the College Museum, 7I'7. Australians give an average of about $68^{\circ} 9$. of the Andaman skeletons, the twenty-one scapulæ which have the epiphyses united give an average index of $69^{\circ} 8$, and thus, in this character also, they stand in close relationship to the Negro and to the Australian. Another sign of inferiority in the scapula of the Andamanese is the almost constant absence of the supra-scapular notch.

The pelvis is also very important for comparison, and the difference that is most obvious and easily estimated lies in the form of the superior aperture or brim, which is always more elongated from before backwards, and narrowed laterally in the apes than it is in man. The relation of the antero-posterior to the transverse diameter of the brim, the latter measurement being taken as IoO, gives the pelvic index. In the anthropoid apes the anteroposterior diameter is always the larger, and in infancy and childhood in our own race the pelvic index is also as high as, or above, 100. In adult man, except in rare cases, the transverse diameter is the greater, and the index consequently below 100 , in the female being lower than in the male. In Europeans the average pelvic index is about $8 \mathrm{I}$ for the male and 78 for the female sex. The average of 17 male Negroes, according to Verneau, is 89 ; of ten Australians, according to Prof. Flower, 98 ; but the Andamanese give the highest figure of all, the average index of 8 males being Ior, the maximum being 16 (the highest index of a human pelvis recorded), the minimum $92^{\circ} 6$. Of the 9 females the average index is $95^{\circ} 2$, the maximum $107^{\circ} 8$, the minimum 86.4 . No race, of which a sufficient number of pelves to give fair averages have been measured, has shown a form of the pelvis departing so widely from the European type. It should be noted, however, that the difference between the sexes is as fully, or even more fully, pronounced than it is in the higher races, contrary to an idea which has been sometimes held, based, however, upon an insufficient number of observations.

Cranial Characters.-The following observations are founded upon twenty-four specimens, all adults, of which twelve belong to the male and twelve to the female sex. They all present a very considerable general resemblance. They present a peculiar combination of characters, which distinguish them from the crania of all other races, unless it may be some of the closely allied Negrito population of the Indian Archipelago. Among these twenty-four skulls none present any artificial or pathological deformation.

In general size the skulls may be considered as belonging to the smallest, or nearly the smallest, of any race. The cranial capacity of the males ranges between $I, I 50$ and $I, 360$ cubic centimetres, the average being $\mathrm{I}, 244 \mathrm{c} . \mathrm{C}$. ( $76 \mathrm{c}$. ins.); that of the females between $I, 025$ and $I, 250$ c.c., the average being I, I 28 c.c. (69 c. ins.), the proportion between the two sexes being, therefore, as $x, 000$ to 906, almost exactly the same as that between English men and women. The average circumference in the male is 480 millimetres; in the female, 462 millimetres.

The general form of the cranium is short and round, and the parietal region is greatly developed at the expense of the frontal, and especially of the occipital regions. The relation of the greatest transverse breadth in the parietal region to the length is expressed by the latitudinal index (sometimes called "cephalic index"). This in both sexes averages 820 , and they are therefore, as a race, truly brachycephalic, all those skulls, the index of which is above 800 , coming into this category. The average index of height-altitudinal index-in both sexes is 775 , being 770 in the males and 779 in the females. In only one out of the twenty-four skulls is the breadth less than the height; they thus differ greatly from the Papuans and Melanesians.

The sutures of the cranium are, as in most inferior races, rather simple. Metopism, or persistence of the midfrontal suture throughout life, occurs in four out of thirtyfour known cases of skulls of Andamanese, and thus seems rather more frequent than among Europeans; this is rather surprising, as it is a character which generally accompanies superiority of development. More skulls, however, must be examined to establish the actual frequency of its occurrence in the race. The disposition of the sutures in the region called pterion by Broca, where the frontal, parietal, squamosal, and alisphenoidal bones meet, is always worthy of note in estimating the differential characters of races. In many inferior races the interval between the frontal and squamosal bones is greatiy diminished, and often, especially among the Melanesians, disappears altogether, the squamosal then directly uniting with the frontal. Very frequently small independent ossicles, or epipteric bones, are interposed.

In the Andamanese the pterion is usually very narrow, but in six only out of forty-six cases examined (taking both sides) did the squamosal reach the frontal. In eight cases epiteric bones were developed. The general surface of the cranium is smooth, and the muscular ridges little pronounced. The forehead is rounded and even, and the glabella and superorbital eminences are always very little developed. The interspace between the orbits is wide and flat, and the orbits are round, the average index, or the ratio of height to width of margin, the latter taken as Ioo, being as high as 910. The nasal bones are straight, with nearly parallel sides, and not prominent. The width of the nasal opening brings the Andamanese into the mesorhine category of Broca, though approaching the platyrhine, the average index being 512. Of the twenty-four skulls, five are platyrhine, seventeen mesorhine, and two leptorhine. With regard to the projection forward of the jaws, eleven are decidedly prognathous, eight mesognathous, and five orthognathous.

Comparison with other Races.-With the Australians, the Andamanese have very little affinity; it is to the other wooly-haired races that we must naturally turn in endeavouring to find their nearest relatives. The typical Melanesians and Papuans differ greatly in their principal cranial characters ; the Tasmanians, also, differed widely from the Andamanese. Many of the African Negroes, again, although usually dolichocephalic, extremely prognathous and platyrhine, have the smooth brow and round orbit seen in the Andamanese, and not generally met with in the true Oceanic Negroes.

The natives of the Andaman Islands, with whom may probably be associated the less known Aetas of the Philippines, the Semangs of the Malay Peninsula, and some other scattered races of the Indo-Malay Peninsula, thus constitute a race apart, to which the name Negrito may properly be applied. At first sight, they appear in their craniological characters to present little affinity to either of the other woolly-haired races, but it is probable that they represent a small or infantile type of the same primary group. It is very possible, but this is purely hypothetical, that the Andamanese may be the unchanged or little modified representatives of a primitive type, from which the African Negroes, on the one hand, and the Oceanic Negroes on the other, have taken their origin, and hence everything connected with their history or structure becomes of the greatest interest to the anthropologist.

\section{The Inhabitants of India}

By their physical characters, the various populations which inhabit the great continent of Asia attach themselves more or less to one or other of two very distinct types:-I. The Mongolian; and II. That which for want of a better name must still be distinguished by the title applied to it by Blumenbach, the Caucasian. 
Roughly speaking, a line striking northward from the head of the Bay of Bengal, to the Himalayas, then turning westward and skirting the southern flanks of that great mountain-chain, passing north of Cashmere, and in a westward direction to the Sea of Aral, the Caspian, and the Ural Mountains, divides the area occupied by people of each type, those to the east and north of this line being mainly Mongolians, and those to the south and west mainly Caucasians.

The people of India proper, except in the extreme north and north-east, belong mainly to the Caucasian division. It has been thought that other races have contributed a share to the composition of the present population of the Peninsula, having been the earliest inbabitants of the land, and forming, as it were, a substratum of the existing population; these are :-I. Negritos, allied to the Andaman Islanders: II. Australoids, allied to the modern Australians. The search for evidence for or against the existence of these elements in the population of India must naturally be sought for among the tribes which retain more or less of their barbarous condition.

With these must be classed the Veddahs of Ceylon. Many of these people have become civilised, but the wild or "Rock Veddahs" live in a most primitive state of social culture, without clothing, agriculture, or fixed dwellings. They are a dwarfish, stunted race, of blackish complexion. and with straight, though generally unkempt and shaggy hair. The condition of their bones and other physical characters give the jmpression of their being a race de - enerated and enfeebled by generations of privation and other circumstances adverse to full development. There are no Veddah skeletons in the College Museum, but as many as seven crania; one of them, that of a woman, is the smallest adult skull in the whole collection, its cerebral capacity measuring only 960 c.c. $(58.6$ c. ins.). They are all dolichocephalic, the average latitudinal index being $7 \mathrm{r}^{\circ} \mathrm{I}$, and the average altidudinal index $86^{\circ} \mathrm{I}$. Their prognathism is not very marked, and the nasal index is medium, averaging $50^{\circ} 3$. They enter rather into the type of the lower grades of the inhabitants of Bengal.

The present population of India, excluding the Mongoloid people of the north and east, is separated by language into two great divisions-(I) The Aryans, and (2) The Non-Aryans, the majority of whom speak one of the agglutinative tongues collectively called Dravidian. The Aryans came into India by the north-west by way of the Punjaub, about I, 500 years before our era, as is supposed. They now occupy the great alluvial plains of the Indus and Ganges between the Himalayas and the elevated plateau of Central India, and have spread southwards along both coasts as far as Ceylon.

The Dravidians, who occupy the greater part of the country southwards from the Nerbudda River, are supposed to be descended mainly from the people who inhabited the country before the Aryan immigration. They are again divided into two groups- $(a)$ The civilised Dravidians, speaking Tamul, Telugu, Canarese, \&c., and $(b)$ The wild tribes of the mountainous districts of the in. terior. These "Hill Tribes," as they are often called, are of great interest to the ethnologist, as they represent the oldest stratum of the population. By their languages they are divided into two groups--(I) Those that speak Dravidian, the Gonds, the Khonds, the Oraons, \&c.; (2) The Munda or Kolarian family, composed of numerous tribes called Coles, Hos, Moondahs, Santals, Billahs, \&c. Very little is known of the physical characters of these people.

Dr. John Shortt has lately sent to the Museum a series of twenty skulls belonging to the tribes of Maravars, who inhabit the Madura district in the south of the peninsula. He has also sent a series of equal number to the Museum of the Paris Anthropological Society, which has been described-by $M$. Callamand in a recent number of the
Rewue d'Anthropologie. As regards the capacity, the average in the Paris skulls is $I, 28 \mathrm{I}$ c.c., in those sent to the Museum, I, 268 c.c. The average lengths are respectively 174.5 and $175^{\circ} 6$, but in the former the projection of glabella is included. The average breadth is $13 \mathrm{I}$ in both; the latitudinal index is 746 in the one and $75 \mathrm{I}$ in the other series; the altitudinal, the nasal, and the orbital indices are respectively 752 and 758,521 and 510,839 , and 854 . These skulls, on the whole, differ totally from those of the Andamanese, especially in the great development of the occipital region. Nor do they present any striking resemblances either to those of the Australians, or to any of the Mongoloid races. Their characters do not differ much from those of the mixed population of Bengal generally. These Maravars may not belong to the races among which the characters of the original hill-tribes should be looked for, and no evidence has yet been found of cranial conformation bearing out the view of the Australian affinities of these people, derived from external appearance. The presence of a Negrito, i.e., woolly-haired and brachycephalic, element in the population of India, is also based at present on very slender evidence.

(To be continued)

\section{ON THE SECULAR EFFECTS OF TIDAL FRICTION ${ }^{1}$}

$\mathrm{T}$ three papers, read at different times before the Royal Society, the author has considered the theory of the tides of a viscous spheroid, and the perturbations of the rotation of the spheroid caused by the attraction of the tide-raising satellite; the direction of that investigation was governed by considerations of applicability to the case of the earth, moon, and sun.

In the paper, of which we are here giving an account, the question is considered both from a more general and from a more special point of view than in the previous papers. For it is here supposed that there is only a single tide-raising body or satellite which moves in a circular orbit in the equator of the planet, but the orbital motion may be either consentaneous with or adverse to the planet's rotation. The tides supposed to be raised in the planet by the attraction of the satellite are of any kind whatever, provided that there is a frictional resistance in the planet to the tidal motion. The results are therefore applicable alike to the hypothesis of bodily tides, or to that of oceanic tides.

It results from a general mechanical principle that in whatever way the satellite and planet interact, the whole moment of momentum of the rotation of the system must remain constant; whilst, as there is a frictional resistance in the planet to the tidal motion, the whole energy of the system, viz., the sum of the potential and kinetic energies, must diminish. The method employed to trace the effects of tidal friction consists in drawing two curves, one of which represents the constancy of the moment of momentum, and the other of which gives the energy of the system for each configuration.

Then if we conceive a system of a planet and satellite started in such a way as to be represented by a given point on the curve of conservation of moment of momentum; and if we imagine this point linked to its corresponding point on the curve of energy, since the energy must degrade, the point on the curve of energy must always slide down a slope and carry with it the point on the curve of momentum.

It is thus possible to track the nature of the changes in the configuration of the system, but the method gives no clue to the time occupied by those changes. This comparison of the energy with the moment of momentum of the system by a graphical method was suggested to the author by Sir William Thomson.

I A paper read before the Royal Cociety on Iure 19, I879, by G. IFo Darwin. 